\title{
Errar Todos os Seres Erram, Persistir no Erro é Humano
}

Mistake Everyone Does, to Insist on the Error is Humane

Existe um velho ditado que reza: "errar é humano, persistir no erro é burrice". Seguramente dizer que é burrice só pode ser no sentido absolutamente figurado de imagens populares. Se observarmos os animais das várias espécies, inclusive os equinos, entre os quais os burros, podemos perceber que eles cometem erros e rapidamente aprendem e não os repetem, não há uma persistência que poderia ser considerada autopunitiva.

Aparentemente nós humanos somos persistentes. Isso fica evidente conforme observamos a história, nacional ou mundial, e também histórias pessoais. Humanos de modo geral não gostam de história e nem de memória. Atualmente, inclusive, se apregoa a ideia de esquecer o passado e viver o presente. Quando se trata de pesquisa se dá importância tão somente àquilo que foi realizado nos últimos cinco anos. Na história em geral se pretende impor que seja aceita a versão dos vencedores. Pouco se valoriza as causas que levaram aos eventos e as consequências dele resultantes e, seguramente, em situações em que existam vencedores e vencidos as consequências podem ser bastante graves.

Da mesma forma nas situações pessoais, quando se classificam pessoas como bem sucedidas - sem se avaliar os caminhos que elas percorreram - podem ser criadas situações muito graves e até induzir a um aprendizado nefasto. É importante lembrar que falta saber o que significa ser uma pessoa bem sucedida, quais seriam os parâmetros para avaliar o sucesso e qual a validade ética desses parâmetros.

Acontece que estamos vivendo conforme esses critérios: vitória $\mathrm{x}$ derrota e sucesso $\mathrm{x}$ insucesso, mesmo sem saber exatamente o que é vitória e o que é sucesso. Isso tem dependido de épocas, modas e de eventuais donos do poder. Para atingir esses objetivos, na maioria das vezes, criamos maneiras e as mais frequentes tem sido os diversos tipos de grupos. Existem os vários tipos de corporações para que pessoas se sintam mais fortes e seguras e estas têm feito e continuam fazendo parte da história. Afinal, vivendo em grupos e adotando a sua filosofia não temos de usar nossa energia 
para pensar, nos sentimos seguros e confortáveis junto àqueles que parecem ser nossos semelhantes e podemos nos permitir atitudes que seriam responsabilidade do grupo ao qual pertencemos. Isso sem falar que nos sentimos apoiados pelo "espírito de corpo" neles existentes e que nos dá suporte até em situações erradas que eventualmente criamos. Participando dessas corporações até corremos o risco de perder a noção de certo e errado e ter como valores aqueles adotados pelo grupo e adotar como certo aquilo que o grupo ou um de seus membros preconiza e considerando errado qualquer ação do grupo diferente, "adversário". A ética passa a inexistir, não mais valem os atos, mas tão somente quem os pratica, e não mais importa a justiça e a legitimidade das ações. Historicamente os grupos existem e são formados com base nos mais diversos princípios: religiosos, econômicos, intelectuais, étnicos, sexuais e nas mais variadas modas que são criadas nos diversos aspectos da vida e nas diferentes épocas. Com isso são estabelecidas classes e castas, amigos e inimigos e os mais variados tipos de preconceitos possíveis face às diversidades entre os grupos. Se esquece que todas as pessoas são diferentes e que essas diferenças são normais e devem ser aceitas. Por exemplo, mulheres e homens são diferentes e isso faz parte da vida e é até necessário para que ela continue. Outro exemplo crianças, adultos e idosos eles são diferentes e sua diferença decorre das mudanças que acontecem no organismo e das experiências que tiveram a oportunidade de ter. Entretanto, atualmente se percebe que até as próprias pessoas sentem dificuldade em aceitar essa evolução natural. Isso acontece muito em função de modas que são propaladas e tem sido secundárias a interesses econômicos, que, às vezes, estão vinculados com frequência ao consumo, ao mercado de trabalho, e predominantemente à necessidade de diminuir ou mesmo abolir o espírito crítico que é aprimorado pela experiência e nem sempre é bem aceito, pois tem sido visto como restrição à rapidez do progresso.

Aparentemente, com o passar do tempo tem acontecido mudanças. $\mathrm{O}$ crescimento dos meios de comunicação tem produzido informações e principalmente a tentativa de tornar tudo uniforme. Entretanto, essa uniformidade teria de atender ao padrão de alguns que pretendem ser o modelo certo o que provavelmente tem como objetivo atender a um sistema global de economia. Cabe a pergunta: existiria um padrão mais correto? Haveria um modo de vida ideal? Qual ele seria? Qual seria o parâmetro para sua avaliação? Seria a felicidade? Seriam os bens materiais possuídos? Se forem as posses, fica mais simples quantificar. Se for a felicidade, o que seria necessário para pessoas serem felizes? Felicidade seria aquilo que tentam nos ensinar diuturnamente de forma subliminar?

Podemos lembrar a colonização das Américas onde os nativos tinham um padrão de vida e os "conquistadores" um padrão completamente diferente. Pela força, os conquistadores predominaram e impuseram seu modo de vida. Os nativos foram rotulados como seres inferiores e preguiçosos, muito embora nunca se tivesse discutido qual das duas populações teria uma vida melhor e mais feliz. Até hoje não se fala nesse aspecto, mesmo com a existência no mundo de inúmeras populações vivendo bem e conforme suas tradições, ainda que os ocidentais entendam que elas teriam uma subvida, pois não consomem tudo aquilo que os ocidentais consomem.

Em relação a usos e costumes e se observam também mudanças que aconteceram 
mais entre os ocidentais nestes últimos 60 anos. Se no inicio do século passado havia acontecido o materialismo comunista, execrado por muitos, no ocidente passou a acontecer o materialismo capitalista que tem sido celebrado como sinônimo de liberdade. Isso justificaria a pretensão do Ocidente de impô-la ao mundo todo. Afinal, nestes últimos 2000 anos, o Ocidente sempre pretendeu ser a verdade e se impor como tal aonde quer que ele tenha contato. Os meios variam desde a força até, o que atualmente é mais frequente, a pressão econômica.

O problema é que o objetivo primordial dessa interferência tem tido finalidade meramente econômica, muito embora pretenda interferir até nos costumes ancestrais, culturais e religiosos, que fazem a diferença entre os povos, o que deveria ser aceito, ao invés de comporta-se como os "conquistadores" das Américas e dar fim àqueles que se opusessem a adotar seus hábitos. Tais costumes deveriam ser aceitos e respeitados, pois se configuram na identidade desses povos. Essas diferenças são apontadas como causas para guerras, atualmente observadas em todos os continentes, resultando numa divisão do mundo entre vencedores e vencidos, e todas as suas outras consequências. Existem as causas religiosas, as diferenças tribais e basicamente o desejo de predominar e ter o poder. E o para que ter o poder? Conforme a economia materialista vigente, o poder tem sido útil para realizar negócios e beneficiar o grupo vencedor. Esse fato tem sido observado em diferentes países nas mais diversas regiões do mundo.

As pessoas costumam pensar confortavelmente que essas coisas, questões de diferenças, acontecem lá e não as afetariam. Entretanto, essas questões de diferenças estão acontecendo em toda parte, inclusive próxima a nós, na sociedade em que convivemos. Somos humanos, tememos as diferenças, queremos estar entre nossos iguais que irão nos proteger e nos dar apoio. Assim adotamos grupos e vivemos no sistema "minha turma x o adversário". Fazemos coisas incríveis para que a turma nos aceite entre seus iguais para então fanaticamente defender os interesses da turma. Quais os interesses da turma? Nem sempre eles são claros, mas isso importa pouco, o que interessa é fazer parte da turma e acreditar que se tem um objetivo comum e que se está protegido e sem ter de fazer maior esforço para pensar, pois já pensaram por nós.

Multiplicam-se as notícias sobre a violência e humilhação que tem acontecido nos processos de aceitação na turma e que, inclusive tem resultado em mortes. Também aumenta a frequência de situações em que existe a turma e aqueles que são diferentes, até porque pensam de forma diversa, passam a ser considerados adversários. Isso tem sido crescente nas torcidas esportivas e não só aí. Notícias sobre diferenças levando à agressão física e mesmo à morte são cada vez mais conhecidas pelo público. Entretanto, os vários tipos de agressões secundárias às diferenças e à formação de grupos estão cada vez mais frequentes e são muito mais problemáticos. Existem corporações de todos os tipos atuando em todas as áreas e produzindo resultados no mínimo discutíveis. Além disso, historicamente sabemos que esse modo de comportamento não é bom para as pessoas e nem para a sociedade e só tem produzido resultados negativos. Isso fica bastante claro nas situações de nepotismo que costumamos condenar.

Pessoas irão dizer que para se conquistar algo tem de agregar as pessoas com objetivos semelhantes para sejam bem sucedidas. Este é um fato que observamos acontecer 
nos diferentes grupos animais, quando eles se unem para suas longas viagens sazonais. É uma questão de cooperação em que os interesses coletivos se sobrepõem aos interesses de corporações.

Por exemplo, quando todos participam e se vota numa assembleia ou numa eleição há o predomínio da maioria; e, mais recentemente, se assinam petições a fim de atuar junto aos poderes públicos. É uma forma de diálogo e entendimento que não ocorre pela força. Ora, pessoas se associarem para usar a força e não o diálogo significa uma "guerra" contra adversário, uma maneira inadequada de se tratar as diferenças, pois só alimenta as animosidades.

Fica aparente que, passados anos e até séculos, os humanos permanecem com os mesmos métodos de criar corporações e "lobbies" e também guetos para resolver seus problemas e, com isso alimentar suas diferenças, apesar da história mostrar que esses métodos têm um resultado bastante discutível. Isso porque eles podem eventualmente derrubar alguns adversários, conseguir alguma vantagem para uns poucos, mas não resolve os problemas que são de todos como, por exemplo, as disparidades sócio econômicas e os problemas ambientais, que permanecem e, muitas vezes, crescem, pois tal comportamento só faz as diferenças aumentarem.

Isso permite pensar que persistir no erro é humano e que se deveria aprender com a história que, para a sociedade, para os países e também para as instituições, cooperação é o fator importante enquanto que corporação é fator negativo e limitante.

DiAnA helenA De benedetTo pozzI professora doutora da Faculdade de Medicina da Universidade de São Paulo (FM-USP) e editora responsável da Revista de Cultura e Extensão USP -e-mail:dianahbp@usp.br 